\title{
Identification and Confirmation of RAPD Markers and Andromonoecious Associated with Quantitative Trait Loci for Sugars in Melon
}

\author{
Jonathan W. Sinclair and Soon O. Park ${ }^{1}$ \\ Vegetable \& Fruit Improvement Center, Texas A\&M University, College Station, TX 77843; Texas \\ Agricultural Research and Extension Center, Texas A\&M University, Weslaco, TX 78596; Department \\ of Horticultural Sciences, Texas A\&M University, College Station, TX 7784
}

Gene E. Lester

U.S. Department of Agriculture, Agricultural Research Service, Kika de la Garza Subtropical Agricultural Research Center, Weslaco, TX 78596

Kil Sun Yoo

Vegetable \& Fruit Improvement Center, Texas A\&M University, College Station, TX 77843; Department of Horticultural Sciences, Texas A\&M University, College Station, TX 77843

Kevin M. Crosby

Vegetable \& Fruit Improvement Center, Texas A\&M University, College Station, TX 77843; Texas Agricultural Research and Extension Center, Texas A\&M University, Weslaco, TX 78596; Department of Horticultural Sciences, Texas A\&M University, College Station, TX 77843

\begin{abstract}
AdDitional Index words. Cucumis melo, sucrose, total soluble solids, sucrose percentage of total sugars, ascorbic acid, randomly amplified polymorphic DNA
\end{abstract}

\begin{abstract}
Our objectives were to identify randomly amplified polymorphic DNA (RAPD) markers associated with quantitative trait loci (QTL) for sucrose, total soluble solids (TSS), and sucrose percentage of total sugars (SPTS) using bulked segregant analysis in an $\mathrm{F}_{2}$ population from the melon (Cucumis melo L.) cross of 'TAM Dulce' (high sugars) x TGR1551 (low sugars) in a greenhouse experiment, and confirm the associations of RAPD markers with QTL for these sugar traits in an $F_{2}$ population from the different cross of 'Deltex' (high sugars) $x$ TGR1551 in a field experiment. Continuous distributions for sucrose, TSS, and SPTS were observed in the $\mathrm{F}_{2}$ populations indicating quantitative inheritance for the traits. Significant positive correlations were found between sucrose and TSS or SPTS. Nine RAPD markers were detected to be significantly associated with QTL for sucrose in the $F_{2}$ population of the 'TAM Dulce' $x$ TGR1551 cross in the greenhouse based on simple linear regression. Five unlinked markers associated with QTL were significant in a stepwise multiple regression analysis where the full model explained $39 \%$ of the total phenotypic variation for sucrose. Five and seven of the nine RAPD markers associated with QTL for sucrose were also observed to be significantly associated with QTL for TSS and SPTS, respectively, suggesting that in this cross three sugar traits are controlled by the same QTL. Five RAPD markers were confirmed in the $F_{2}$ population of the 'Deltex' $x$ TGR1551 cross in the field to be consistently associated with QTL for three sugar traits. Significant associations of andromonoecious (a) with both sucrose and TSS were consistently expressed in our populations under greenhouse and field environments. These RAPD and floral markers associated with the sugar synthesis QTL identified and confirmed here could be useful in melon breeding for improving the mature fruit sweetness.
\end{abstract}

Melon fruit flesh is a significant source of ascorbic acid, folic acid, and potassium (Richter, 2000) and if orange-fleshed a very significant source of beta-carotene (Lester, 1997) as well as free sugars and water (Martyn and Miller, 1996). Sugars are known to be accumulated within the ripe fruit due to a result of complex source-sink relationships conditioning the metabolism of assimilates and their partitioning (Schaffer et al., 1996). Soluble sugars present in the ripe melon fruit are mainly composed of sucrose, fructose, and glucose (Burgeret al., 2002; Hughes and Yamaguchi,

Received for publication 21 Sept. 2005. Accepted for publication 12 Feb. 2006. This research was funded in part by USDA Grant: 2001-34402-10543, "Designing Foods for Health." We acknowledge financial support from the South Texas Melon Committee. We also appreciate the constructive criticism of two reviewers, Drs. Marvin Miller and John Robinson, Texas Agricultural Research and Extension Center, Texas A\&M Univ., to improve the manuscript. We also thank technicians Kay Harding and Hyun J. Kang, Texas Agricultural Research and Extension Center, for their assistance.

${ }^{1}$ Corresponding author: so-park@tamu.edu.
1983; Lester and Dunlap, 1985; McCollum et al., 1988). Mature fruit sweetness, regarded as the best fruit quality determinant in melon, is directly affected by the concentration of the three sugar components (Yamaguchi et al., 1977). Particularly, the accumulation of sucrose predominantly leads to the enhancement of total sugar concentration at the stage of fruit maturation (Hubbard et al., 1989; Hughes and Yamaguchi, 1983; Lester and Dunlap, 1985; McCollum et al., 1988; Pratt, 1971; Rosa, 1928; Schaffer et al., 1996). Vitamin C, also known as ascorbic acid (AA), is an important nutrient for human health (Adams and Richardson, 1981). It functions as a water soluble antioxidant in the human body (Lavine, 1986). It also plays a crucial role in keeping the immune system healthy (Eichholzer et al., 2001).

Due to consumer preference for sweet fruit (Lester and Shellie, 1992), sugar content is a highly important quality trait of different market melon classes (U.S. Government Printing Office, 1990). The improvement of sugar content is one of the most significant goals in breeding programs of most melon types worldwide. 
Burger et al. (2002) reported a single recessive gene controlling sucrose accumulation in melon. Sucrose was found to be positively correlated with TSS (Park et al., 2004b). Intermediate positive correlations of TSS with overall consumer preference, sweetness, flavor, texture (Lester and Shellie, 1992), and maturation period (Welles and Buitelaar, 1988) were reported. Burger et al. (2002) calculated both broad (0.39-0.81) and narrow (0.27-0.72) sense heritability estimates for sucrose in three melon populations. They also estimated narrow sense heritability for glucose $(0.18-0.27)$ and fructose (0.35). Moderately high narrow sense heritability for TSS was reported by Kalb and Davis (1984).

Bulked segregant analysis (BSA) (Michelmore et al., 1991) is an efficient method to rapidly identify molecular markers linked to a specific gene using DNA bulks from $\mathrm{F}_{2}$ plants. This technique, along with RAPD, has been used to tag the $m s-3$ gene controlling male sterility (Park et al., 2004c) as well as genes for disease and pest resistance such as the dominant Fom 2 gene for resistance to fusarium wilt caused by Fusarium oxysporum Schlechtend.:Fr. f.sp. melonis W.C. Snyder \& H.N. Hans. (Wechter et al., 1995), the dominant Vat gene for resistance to cotton-melon aphid (Aphis gossypii Glover) (Klingler et al., 2001), and the recessive $n s v$ gene for resistance to melon necrotic spot virus (Morales et al., 2002) in melons. Also, it has been applied in identifying QTL affecting mature melon fruit sweetness, size, and shape traits (Park and Crosby, 2004; Park et al., 2004b).

Introducing high sugar genes into low or intermediate sugar cultivars and breeding lines is a strategy recommended for improving mature melon fruit sweetness. Molecular markers linked to QTL regulating synthesis of sugar components would be useful in transferring these QTL into low sugar melon cultivars and lines. Molecular mapping of QTL for sugar-related traits has been reported in several horticultural crops such as tomato (Lycopersicon esculentum Mill.) (Causse et al., 2002), peach [Prunuspersica(L.) Batsch] (Etienne etal., 2002), and watermelon [Citrullus lanatus (Thunb.) Matsum and Nakai] (Hashizume et al., 2003). Those markers linked to QTL for sugars may improve the breeder's ability to recover high sugar genotypes and aid in the development of high sugar elite cultivars. However, markers associated with QTL affecting sugars present in 'TAM Dulce', a western shipper muskmelon type, have not been reported.

Our objective in the current study was to identify RAPD and andromonoecious $(a)$ markers associated with QTL controlling AA as well as seven sugar traits such as TSS, sucrose, glucose, fructose, SPTS, glucose percentage of total sugars (GPTS), and fructose percentage of total sugars (FPTS) by means of BSA in an $\mathrm{F}_{2}$ population derived from the melon cross of 'TAMDulce' (high sugars and AA) X TGR1551 (low sugars and AA) in a greenhouse experiment. Park et al. (1999) emphasized the importance of confirming the marker-QTL associations in different populations and environments before using molecular markers for marker-assisted selection (MAS) in breeding programs. Thus, our additional goal was to confirm the associations of RAPD and flower markers with QTL for these sugar and AA traits in an $F_{2}$ population from the different cross of 'Deltex' (high sugars and AA) X TGR1551 in a field experiment. Pearson correlations between the sugar and AA traits were also calculated in the populations.

\section{Materials and Methods}

Plant materials. One hundred-five $F_{2}$ plants were derived from the melon cross of 'TAM Dulce' $x$ TGR1551 for identification of sugar-related QTL in a greenhouse at the Texas Ag- ricultural Research and Extension Center (TAREC)-Weslaco, Texas A\&M Univ., in Spring 2002. The 'TAM Dulce' parent, a western shipper muskmelon type with high fruit quality, was developed at the TAREC-Weslaco (Kunkel, 1968). 'TAM Dulce' is resistant to powdery mildew caused by Sphaerotheca fuliginea (Schlechtend.:Fr.) Pollacci (races 1 and 2), downy mildew caused by Pseudoperonospora cubensis (Berk. \& M.A. Curtis) Rostovzev, and fusarium wilt (race 2). The TGR1551 parent, originally obtained from Zimbabwe, is a wild type with low fruit quality. TGR1551 is highly resistant to cucurbit yellow stunting disorder virus under natural and controlled-inoculation conditions (Lopez-Sese and Gomez-Guillamon, 2000). Sixty-four $\mathrm{F}_{2}$ plants were derived from the cross of 'Deltex' $x$ TGR1551 in the greenhouse at the TAREC-Weslaco in Winter 2002. The high sugar 'Deltex' parent, a commercial ananas cultivar (Nunhems, Parma, Idaho), is resistant to fusarium wilt (races 0 and 2). We used this $\mathrm{F}_{2}$ population for confirmation of the marker-QTL associations. Eight fruit quality characteristics of the three parents are indicated in Figs. 1 and 2.

One hundred-five $\mathrm{F}_{2}$ plants with the parents 'TAM Dulce' and TGR 1551 were planted in the greenhouse at the TAREC-Weslaco on 15 Oct. 2002. One plant was grown per 11-L pot containing soil-less media, Sunshine Mix \#4 (Sun Gro Horticulture, Bellevue, Wash.). Peters 20N-8.7P-16.6K water-soluble fertilizer (Scotts, Marysville, Ohio) was applied weekly. Pesticides were applied as needed to control diseases including powdery mildew and pests such as white flies (Bemisia tabaci Gennadius), spider mites (Tetranynchus urticae Koch), and aphids. Approximate day/night greenhouse temperatures were $25 \pm 3 / 22 \pm 2{ }^{\circ} \mathrm{C}$. Day lengths ranged from 12 to $10 \mathrm{~h}$ light in this experiment.

Sixty-four $\mathrm{F}_{2}$ plants along with 10 plants each of the parents, 'Deltex' and TGR1551, were planted on black plastic mulch with drip irrigation on sandy clay loam soil at Weslaco, Texas on 10 Mar. 2005. Single bed length and width were 31.7 and 1.0 $\mathrm{m}$, respectively, with $30.5 \mathrm{~cm}$ spacing between plants and $1.0 \mathrm{~m}$ between beds. A fertilizer containing 5N-11.3P-27.4K (Wilbur Ellis, Edinburg, Texas) was applied weekly. Irrigation was supplied as needed. Approximate day/night field temperatures were $30 \pm 3 / 23 \pm 3{ }^{\circ} \mathrm{C}$. Day lengths ranged from 12 to $14 \mathrm{~h}$ light.

Data collection. Total soluble solids data were obtained from the two parental pairs as well as the 105 and $64 \mathrm{~F}_{2}$ plants using a temperature corrected refractometer with digital readout (Reichert Scientific Instruments, Buffalo, N.Y.). Fruit sugars were extracted from $0.5 \mathrm{~g}$ lyophilized tissue by stirring in $5 \mathrm{~mL}$ of $80 \%$ ethanol at $90{ }^{\circ} \mathrm{C}$ for $2 \mathrm{~min}$. The solution was filtered (No. 1; Whatman International Ltd., Maidstone, U.K.) and the residue washed with an additional $5 \mathrm{~mL}$ of $80 \%$ ethanol $\left(90^{\circ} \mathrm{C}\right)$. One milliliter of the extract was filtered through a pre-wetted, (with $80 \%$ ethanol) C18 Sep-Pak (Waters Corp., Milford, Mass.) before determination of sucrose, glucose, and fructose levels using the high-performance liquid chromatography procedure previously described by Lester and Dunlap (1985). Data for SPTS, GPTS, and FPTS were also calculated for the $\mathrm{F}_{2}$ plants and the parents. Ascorbic acid content of each plant was recorded using the procedure of Hodges et al. (2001). Stamen presence and absence in female flowers were checked thrice on all plants of $\mathrm{F}_{2}$ and parents at different times during flowering.

RAPD. Fully expanded leaves of the 105 and $64 \mathrm{~F}_{2}$ plants along with their parental pairs were collected at $21 \mathrm{~d}$ after planting. Total genomic DNA was extracted from the leaf tissue using the method of Skroch and Nienhuis (1995). A total of 500 random 10-mer primers (Operon Technologies, Alameda, Calif.) were 

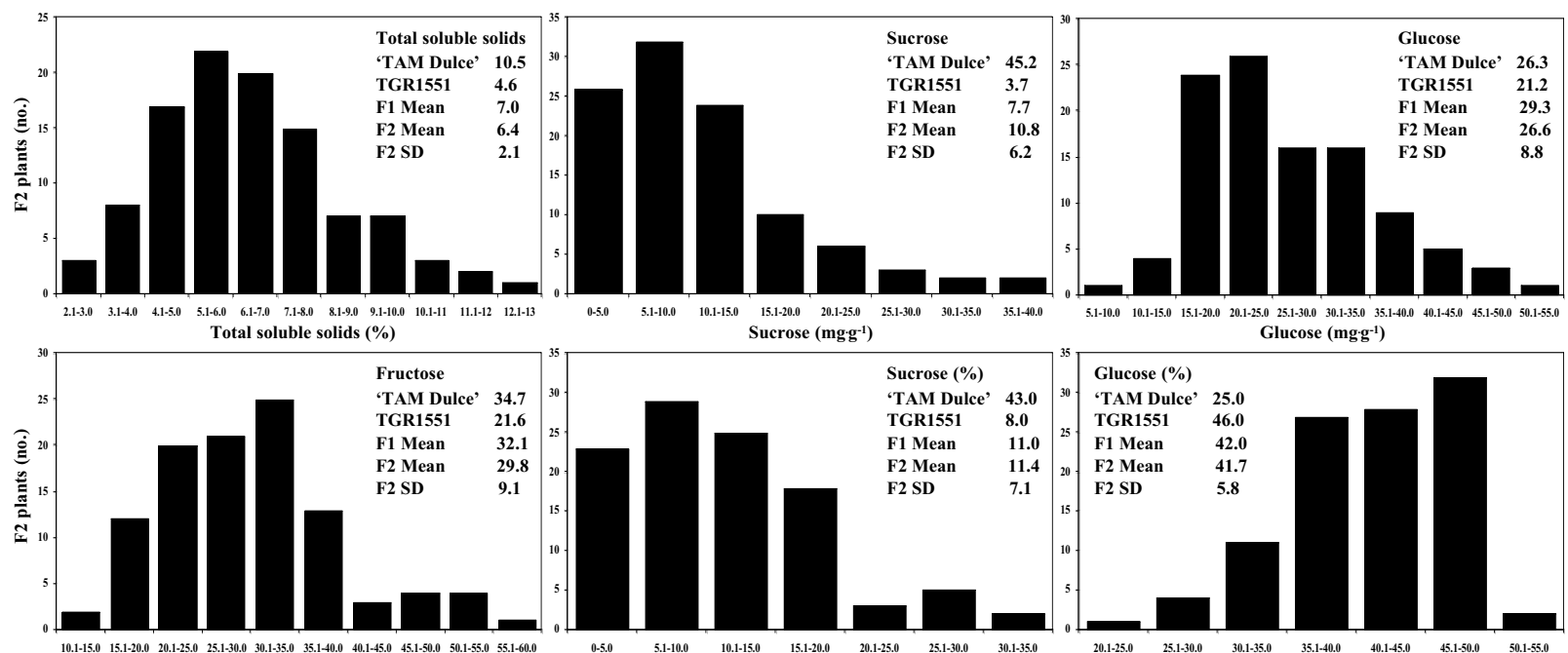

Glucose (mg.g-1)
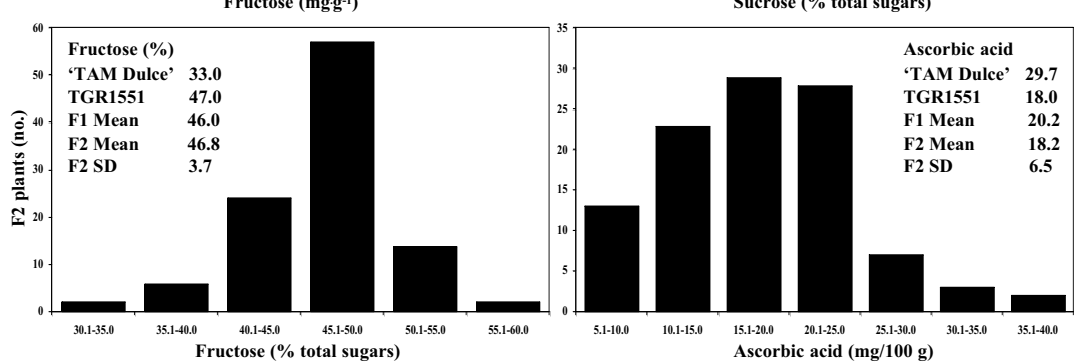

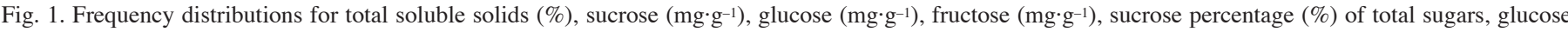

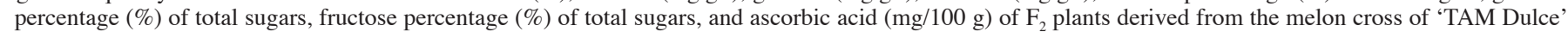
$\mathrm{x}$ TGR1551 in the greenhouse experiment.
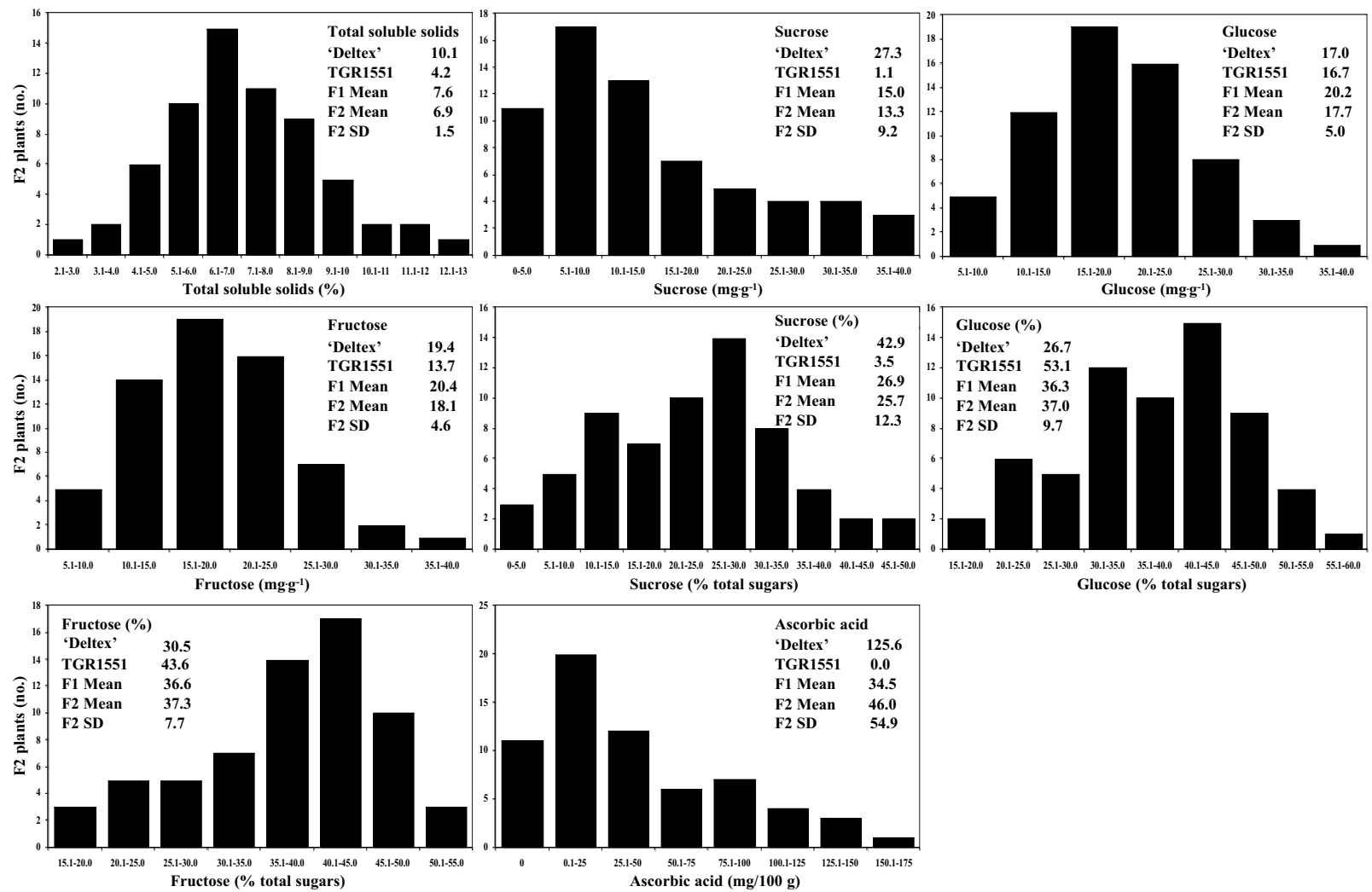

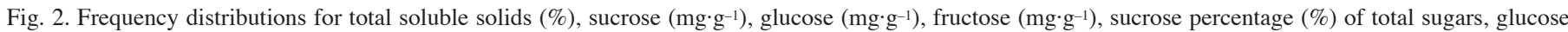
percentage $(\%)$ of total sugars, fructose percentage $(\%)$ of total sugars, and ascorbic acid (mg/100 g) of $\mathrm{F}_{2}$ plants derived from the melon cross of 'Deltex' $\mathrm{x}$ TGR1551 in the field experiment. 
used for the RAPD analysis (Williams et al., 1990). Polymerase chain reactions (PCR) were performed on 96-well plates in a MJ Research thermalcycler (model PTC-0100; MJ Research, Waltham, Mass.). Protocols for PCR and the composition of the final volume of reactants were the same as those described by Skroch and Nienhuis (1995). A 100-base pair (bp) DNA ladder (Life Technologies, Grand Island, N.Y.) was used to estimate the length of RAPD markers. The name of each RAPD marker is derived from an "O" prefix for Operon primers, the letters identifying the Operon kit, Operon primer number, and the approximate length (bp) of the marker (Park et al., 2004a).

Bulked SEGREganT ANALYSIS. Three low and high bulk pairs were prepared from equal volumes of standardized DNA $\left(10 \mathrm{ng} \cdot \mathrm{L}^{-1}\right)$ from eight selected $F_{2}$ plants of the 'TAM Dulce' $x$ TGR1551 cross with the highest and lowest values for TSS, sucrose, and AA, respectively. Bulks for sucrose were also regarded as ones for SPTS because selected $\mathrm{F}_{2}$ plants with the highest and lowest values for sucrose were identical to those for SPTS. The 500 primers were used to simultaneously screen between the low and high DNA bulks, and between the parents 'TAM Dulce' and TGR1551. Primers that generated marker polymorphisms between the low and high DNA bulks for TSS, sucrose (or SPTS) or AA were tested in the $\mathrm{F}_{2}$ population from the cross between 'TAM Dulce' and TGR1551 for identifying QTL. Eleven primers were tested in the $F_{2}$ population of the 'Deltex' $x$ TGR1551 cross for confirming the RAPD marker-QTL associations.

LiNKAGE ANALYSIS. To detect segregation distortion of markers and andromonoecious, $\mathrm{F}_{2}$ population marker data were tested for goodness-of-fit to a 3:1 ratio using the chi-square test. Due to the dominant nature of RAPD markers, the linkage analyses of five markers obtained from 'TAM Dulce' and 11 markers including $a$ obtained from TGR1551 were separately performed on the data for $105 \mathrm{~F}_{2}$ plants of the 'TAM Dulce' $\mathrm{x}$ TGR1551 cross using MAPMAKER version 3.0 (Lander et al., 1987). We also executed separately the linkage analyses of three markers from 'Deltex' and nine markers from TGR1551 on the data for $64 \mathrm{~F}_{2}$ plants of the 'Deltex' $x$ TGR1551 cross. Map distances (centimorgans) between ordered loci of markers and $a$ were calculated using recombination fractions and the Kosambi mapping function (Kosambi, 1944).

Detection of QTL. Simple linear regression (SLR), for each pairwise combination of quantitative traits and marker loci, was used to analyze the greenhouse and field data for detection and confirmation of QTL for TSS, sucrose, glucose, fructose, SPTS, GPTS, FPTS, and AA content. Significant differences in trait associations were based on $\mathrm{F}$ tests $(P<0.05)$ (Edwards et al., 1987). Loci with the lowest $P$ value per QTL were chosen and then were added in a stepwise multiple regression (SMR) to select the best set of markers $(P<0.05)$ for prediction of the total trait phenotypic variation explained by the identified QTL (Paterson et al., 1991). Pearson correlations of mature fruit quality traits including three sugars and AA were also determined in our populations. All statistical analyses were conducted using SAS (SAS Institute, Cary, N.C.).

\section{Results and Discussion}

FREQUENCY DISTRIBUTIONS FOR FRUIT SWEETNESS TRAITS. Clear separations were observed for TSS, sucrose, and fructose content between 'TAM Dulce' and TGR1551 in the greenhouse experiment, whereas a slight difference was found for glucose content (Fig. 1). Mature fruits of 'TAM Dulce' had high TSS $(9.1 \%$ to
$12.5 \%)$ and sucrose $\left(34.6-65.8 \mathrm{mg} \cdot \mathrm{g}^{-1}\right)$ content. In contrast, those of TGR1551 possessed low TSS (3.8\% to 5.8\%) and sucrose $\left(0.0-4.7 \mathrm{mg} \cdot \mathrm{g}^{-1}\right)$ content. Fruits of all $\mathrm{F}_{1}$ plants derived from the 'TAM Dulce' $x$ TGR1551 cross had intermediate TSS and low sucrose content (Fig. 1). A frequency distribution for sucrose was skewed towards low values. Continuous frequency distributions for TSS, sucrose, glucose, and fructose content were noted for $\mathrm{F}_{2}$ plants of the 'TAM Dulce' $x$ TGR1551 cross in the greenhouse (Fig. 1), indicating that the fruit sugar traits were quantitatively inherited. In addition, continuous distributions for these sugar traits were observed for $F_{2}$ plants of the 'Deltex' $x$ TGR1551 cross in the field (Fig. 2) consistent with the quantitative inheritance for the traits.

The quantitative inheritance pattern of sucrose concentration found here agrees with the finding of Burger et al. (2002), who reported that the sucrose trait was governed by major and other genes in two segregating populations derived from melon crosses between a high sugar parent 'Noy Yizre'el' and an intermediate sugar parent Persia 202 in a field experiment. However, they also reported a single recessive gene $(s u c)$ controlling high sucrose content in $\mathrm{F}_{2}$ and backcross populations from crosses of the high sugar cultivar Noy Yizre'el with a low sugar cultivar Faqqous in field experiments. This result of the single recessive gene was not confirmed in the subsequent $\mathrm{F}_{3}$ generation. Low narrow-sense heritability for sucrose was noted in the high $\mathrm{x}$ intermediate sugar cross, while moderately high heritability was observed in the high x low sugar cross (Burger et al., 2002).

The complex inheritance pattern of TSS concentration in this study was similar to that reported previously in other horticultural crops (Causse et al., 2002; Etienne et al., 2002; Georgelis et al., 2004; Hashizume et al., 2003; Paterson et al., 1991) as well as melon (Burger et al., 2002). Low (0.23), intermediate (0.63-0.66), and high (0.75) estimates of narrow sense heritability for TSS were reported in several genetically different melon populations (Burger et al., 2002; Kalb and Davis, 1984). Burger et al. (2002) and Etienne et al. (2002) reported quantitative inheritance patterns of glucose and fructose content in melon and peach. Burger et al. (2002) found low narrow sense heritability for glucose and fructose in the high $\mathrm{x}$ low and high $\mathrm{x}$ intermediate sugar crosses.

We noted clear differences for three individual sugar compositions between the two parents in the greenhouse (Fig. 1). 'TAM Dulce' possessed high SPTS, and TGR1551 had high GPTS and FPTS. All $F_{1}$ plants derived from the 'TAM Dulce' $x$ TGR1551 cross possessed low SPTS and high GPTS and FPTS. Frequency distributions for SPTS and GPTS were skewed towards low and high values, respectively. We observed continuous distributions for SPTS, GPTS, and FPTS in the $\mathrm{F}_{2}$ plants of the 'TAM Dulce' $x$ TGR1551 cross in the greenhouse (Fig. 1) suggesting quantitative inheritance for the three traits. We confirmed the quantitative inheritance patterns of the three individual sugar compositions in the 'Deltex' $x$ TGR1551 cross in the field (Fig. 2).

Distinct separations for AA content between the parents were found (Figs. 1 and 2). Fruits of 'TAM Dulce' and 'Deltex' had high AA content. In contrast, TGR1551 plants possessed low AA content. All $\mathrm{F}_{1}$ plants derived from two melon crosses had low AA content. We noted skewed distributions for AA towards low values. Continuous distributions for AA content were observed in two $\mathrm{F}_{2}$ populations in the greenhouse and field (Figs. 1 and 2) indicating quantitative inheritance for the quality trait. Complex inheritance patterns of three organic acids (Etienne et al., 2002) and two antioxidant compounds (Causse et al., 2002) were also reported in other crops. 
CORRELATION OF SUCROSE WITH OTHER SWEETNESS TRAITS. Sucrose accumulation was observed to be significantly and positively correlated with TSS content and SPTS in the two $\mathrm{F}_{2}$ populations in the greenhouse and field experiments (Table 1), indicating that selection of the three fruit sweetness traits is feasible. The positive correlation between sucrose and TSS content was nearly the same as that reported previously in peach by Etienne et al. (2002). Significant negative correlations of sucrose content with GPTS and FPTS were found in the two genetic populations. A significant positive correlation was noted between glucose and fructose content present in mature melon fruit. This high correlation of glucose with fructose content found here was consistent with the result of Etienne et al. (2002). We observed significant negative correlations of SPTS with GPTS and FPTS in the greenhouse and field.

RAPD MARKERS FOR FRUIT SWEETNESS TRAITS. A total of 500 primers were used for the RAPD analysis of three different bulk pairs developed from selected greenhouse $F_{2}$ plants with low and high values for fruit quality traits along with their parents 'TAM Dulce' and TGR1551. Forty-five RAPD markers were polymorphic between the low and high bulk pairs of TSS, sucrose (or SPTS), and AAconcentrations. Fifteen displayed an amplified DNA fragment in the high DNA bulk that was absent in the low DNA bulk. Thirty showed an amplified DNA fragment in the low bulk that was absent in the high bulk. An example of marker OAA09.350 is shown in Fig. 3. These 45 marker fragments segregated in the $\mathrm{F}_{2}$ population of the 'TAM Dulce' $x$ TGR1551 cross. Of the 45 markers, 15 were identified to be associated with at least one of the fruit quality traits on the basis of statistical analysis, whereas 30 were proven to be false positives. A goodness-of-fit to a 3:1 ratio for band presence to band absence for each of the
15 markers was observed in $105 \mathrm{~F}_{2}$ plants (Table 2). Of 10 identified markers that displayed an amplified DNA fragment in the low bulk, four were linked within a distance of $8.5 \mathrm{~cm}$ on one linkage group (LG). These four linked markers were associated with only the AA trait. However, the remaining six markers were not linked in the population. Five identified markers that showed an amplified DNA fragment in the high bulk were unlinked on the basis of linkage analysis, suggesting that they are located on different chromosomes.

Of seven sugar traits, three (TSS, sucrose, and SPTS) were chosen for the BSA analysis because they are major factors determining mature fruit sweetness and importance in melon breeding for enhancing the fruit sweetness. All seven sugar traits were mostly correlated in our greenhouse population (Table 1). According to the results of Paterson et al. (1991) in tomato and Park et al. (1999) in common bean (Phaseolus vulgaris L.), correlated traits usually possessed common genetic markers associated with them. Therefore, RAPD markers linked to TSS, sucrose, and SPTS identified by BSA were also used to continuously search their associations with other four minor sugar traits including glucose, fructose, GPTS, and FPTS in the greenhouse population.

RAPD markers linked to quantitative genes for fruit size and shape traits as well as qualitative genes for pest and disease resistance have been detected successfully by means of BSA in melons (Klingler et al., 2001; Morales et al., 2002; Park and Crosby, 2004; Wechter et al., 1995). Quantitative loci for fruit sweetness traits were mapped in genetic linkage maps of several horticultural crops using different types of molecular markers (Causse et al., 2002; Etienne et al., 2002; Hashizume et al., 2003). This is the first report of molecular markers highly associated

Table 1. Pearson correlations of total soluble solids (TSS), sugars, and ascorbic acid (AA) in two $\mathrm{F}_{2}$ populations derived from melon crosses of 'TAM Dulce' $x$ TGR1551 (TT) and 'Deltex' $\mathrm{x}$ TGR1551 (DT) in greenhouse and field experiments.

\begin{tabular}{lcccccccc}
\hline & & \multicolumn{6}{c}{ Fruit quality traits } \\
\cline { 3 - 9 } Traits & Cross & TSS & Sucrose & Glucose & Fructose & SPTS $^{z}$ & GPTS & FPTS \\
\hline \multirow{2}{*}{ AA } & TT & $0.06^{\mathrm{NS}}$ & $0.15^{\mathrm{NS}}$ & $-0.08^{\mathrm{NS}}$ & $0.12^{\mathrm{NS}}$ & $0.23^{*}$ & $-0.39^{* *}$ & $0.17^{\mathrm{NS}}$ \\
& DT & $0.39^{* *}$ & $0.57^{* *}$ & $-0.47^{* *}$ & $-0.11^{\mathrm{NS}}$ & $0.54^{* *}$ & $-0.62^{* *}$ & $-0.36^{* *}$ \\
FPTS & TT & $-0.37^{* *}$ & $-0.62^{* *}$ & $-0.30^{* *}$ & $-0.13^{\mathrm{NS}}$ & $-0.58^{* *}$ & $0.07^{\mathrm{NS}}$ & \\
& DT & $-0.48^{* *}$ & $-0.89^{* *}$ & $0.64^{* *}$ & $0.73^{* *}$ & $-0.92^{* *}$ & $0.76^{* *}$ & \\
GPTS & TT & $-0.16^{\mathrm{NS}}$ & $-0.70^{* *}$ & $0.24^{*}$ & $-0.13^{\mathrm{NS}}$ & $-0.85^{* *}$ & & \\
& DT & $-0.52^{* *}$ & $-0.94^{* *}$ & $0.79^{* *}$ & $0.40^{* *}$ & $-0.95^{* *}$ & & \\
SPTS & TT & $0.33^{* *}$ & $0.89^{* *}$ & $-0.03^{\mathrm{NS}}$ & $0.18^{\mathrm{NS}}$ & & & \\
& DT & $0.53^{* *}$ & $0.98^{* *}$ & $-0.77^{* *}$ & $-0.59^{* *}$ & & & \\
Fructose & TT & $0.96^{* *}$ & $0.51^{* *}$ & $0.89^{* *}$ & & & & \\
& DT & $-0.08^{\mathrm{NS}}$ & $-0.48^{* *}$ & $0.74^{* *}$ & & & & \\
Glucose & TT & $0.90^{* *}$ & $0.32^{* *}$ & & & & & \\
& DT & $-0.20^{\mathrm{NS}}$ & $-0.69^{* *}$ & & & & & \\
Sucrose & TT & $0.66^{* *}$ & & & & & & \\
& DT & $0.57^{* *}$ & & & & & & \\
\end{tabular}

$\overline{{ }^{2} \text { SPTS }}=$ sucrose percentage of total sugars, GPTS = glucose percentage of total sugars, FPTS $=$ fructose percentage of total sugars.

NS,***Nonsignificant or significant at $P \leq 0.05$ or 0.01 , respectively. 


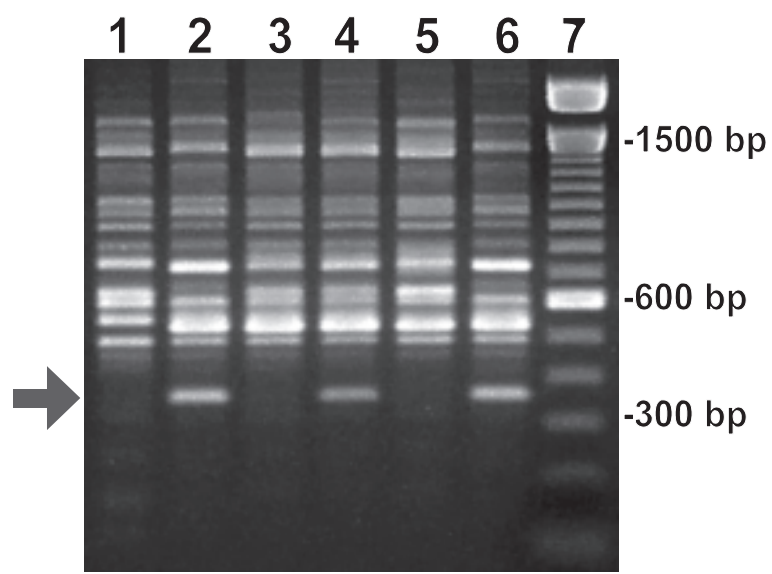

Fig. 3. RAPD marker OAA09.350 expressing polymorphism between two DNA bulks from high and low sucrose melon $\mathrm{F}_{2}$ plants, between the high sucrose parent 'TAM Dulce' and the low sucrose parent TGR1551, and between the high sucrose parent 'Deltex' and the low sucrose parent TGR1551. 1 ='TAM Dulce', 2 = TGR1551, 3 = DNA bulk from eight high sucrose $\mathrm{F}_{2}$ plants, $4=$ DNA bulk from eight low sucrose $\mathrm{F}_{2}$ plants, 5 = 'Deltex', 6 =TGR1551, and 7 $=\mathrm{a}$ 100-bp DNA marker ladder.

with QTL affecting comprehensive sugar-related traits by means of BSA in melon.

Pitrat (1991) developed a partially classical melon linkage map consisting of 28 vegetative, floral and disease resistance markers distributed on eight LGs and five unlinked loci. Molecular genetic linkage maps of melon constructed on the basis of various types of molecular markers such as isozyme, RAPD, RFLP, simple sequence repeat(SSR), amplified fragment length polymorphism, and resistance gene homologues have been reported (BaudraccoArnas and Pitrat, 1996; Brotman et al., 2000; Danin-Poleg et al., 2000, 2002; Oliver et al., 2001; Perin et al., 2002b; Wang et al., 1997). Due to different parental genotypes and genetic markers, few common phenotypic or SSR markers that were connected among linkage maps, were found (Danin-Poleg et al., 2001; Pitrat, 2002) and thus, no saturated reference melon map is currently available. Of the 15 RAPD markers associated with loci for at least one of our eight targeted traits, only OAP03.800 was noted to be linked to the andromonoecious gene at $26.4 \mathrm{cM}$ in this population. Pitrat (2002) reported the common flower $a$ marker on LG D, LG 3, LG 8, LG II, and LG IV in five molecular linkage maps, respectively, as well as LG 4 in the classical linkage map. Thus, OAP03.800 was included in the classical and molecular maps. The other 14 RAPD markers associated were not included in the published melon maps.

QTL FOR TOTAL SOLUBLE SOLIDS. A total of six genetic markers including five RAPDs and andromonoecious were identified to be significantly associated with QTL affecting TSS content in the $F_{2}$ population of the 'TAM Dulce' $x$ TGR1551 cross in the greenhouse experiment based on SLR (Table 3). Two markers were amplified from 'TAM Dulce,' while four markers were generated from TGR1551. The high TSS parent 'TAM Dulce' contributed high TSS alleles for these six markers (Table 4). Markers OAW06.1250 from 'TAM Dulce' and OAS03.450 from TGR 1551 explained $9 \%$ and $8 \%$ of the variation for the TSS content, respectively. Also, OAT03.250, OAP03.800, OAW06.600, and the $a$ locus accounted for $4 \%$ to $7 \%$ of the variation. The two unlinked makers from 'TAM Dulce' and the three unlinked markers from TGR1551 explaining 14\% and 19\% of the total variation for the trait, respectively, were significant in the SMR analysis (Table 5).

In tomato, peach, and watermelon one to two major QTL influencing soluble solids content were observed by several investigators (Causse et al., 2002; Etienne et al., 2002; Georgelis et al., 2004; Hashizume et al., 2003), while seven minor QTL related to the TSS content in tomato were found by Paterson et al. (1991).

Table 2. Chi-square analyses for segregation of 15 RAPD markers and andromonoecious $(a)$ associated with fruit quality traits in two $\mathrm{F}_{2}$ populations derived from melon crosses of 'TAM Dulce' x TGR1551 (TT) and 'Deltex' x TGR1551 (DT).

\begin{tabular}{|c|c|c|c|c|c|c|c|c|c|c|c|}
\hline \multirow[b]{2}{*}{ Marker $^{2}$} & \multirow[b]{2}{*}{ Source } & \multicolumn{2}{|c|}{ TT plants (no.) } & \multirow[b]{2}{*}{ Ratio } & \multirow[b]{2}{*}{$\chi^{2}$} & \multirow[b]{2}{*}{$P$} & \multicolumn{2}{|c|}{ DT plants (no.) } & \multirow[b]{2}{*}{ Ratio } & \multirow[b]{2}{*}{$\chi^{2}$} & \multirow[b]{2}{*}{$P$} \\
\hline & & Presence & Absence & & & & Presence & Absence & & & \\
\hline OAT03.1600 & TAM Dulce & 79 & 26 & $3: 1$ & 0.00 & 0.96 & & & $3: 1$ & & \\
\hline OAU13.1350 & TAM Dulce \& Deltex & 75 & 30 & $3: 1$ & 0.53 & 0.46 & 51 & 13 & $3: 1$ & 0.52 & 0.47 \\
\hline OAW06.1250 & TAM Dulce \& Deltex & 80 & 25 & $3: 1$ & 0.02 & 0.87 & 55 & 9 & $3: 1$ & 3.52 & 0.06 \\
\hline OAW06.1100 & TAM Dulce & 80 & 25 & $3: 1$ & 0.02 & 0.87 & & & $3: 1$ & & \\
\hline OAT03.250 & TAM Dulce \& Deltex & 75 & 30 & $3: 1$ & 0.53 & 0.46 & 44 & 20 & $3: 1$ & 1.01 & 0.31 \\
\hline OAA09.350 & TGR1551 & 82 & 23 & $3: 1$ & 0.38 & 0.54 & 42 & 22 & $3: 1$ & 2.52 & 0.11 \\
\hline OAP03.800 & TGR1551 \& Deltex & 81 & 24 & $3: 1$ & 0.15 & 0.69 & & & $3: 1$ & & \\
\hline OAQ13.750 & TGR1551 & 79 & 26 & $3: 1$ & 0.00 & 0.96 & 43 & 21 & $3: 1$ & 1.68 & 0.19 \\
\hline OAS03.450 & TGR1551 & 70 & 35 & $3: 1$ & 3.45 & 0.06 & 41 & 23 & $3: 1$ & 3.52 & 0.06 \\
\hline OAS14.800 & TGR1551 & 72 & 33 & $3: 1$ & 1.98 & 0.16 & 52 & 12 & $3: 1$ & 1.01 & 0.31 \\
\hline OAU02.600 & TGR1551 & 72 & 33 & $3: 1$ & 1.98 & 0.16 & 51 & 13 & $3: 1$ & 0.52 & 0.47 \\
\hline OAU03.700 & TGR1551 & 72 & 33 & $3: 1$ & 1.98 & 0.16 & 50 & 14 & $3: 1$ & 0.18 & 0.66 \\
\hline OAU05.600 & TGR1551 & 77 & 28 & $3: 1$ & 0.08 & 0.78 & 53 & 11 & $3: 1$ & 1.68 & 0.19 \\
\hline OAW 10.400 & TGR1551 & 70 & 35 & $3: 1$ & 3.45 & 0.06 & 42 & 22 & $3: 1$ & 2.52 & 0.11 \\
\hline OAW06.600 & TGR1551 \& Deltex & 80 & 25 & $3: 1$ & 0.02 & 0.87 & & & $3: 1$ & & \\
\hline$a$ & TGR1551 & $\begin{array}{c}74 \\
\text { (monoecious) }\end{array}$ & $\begin{array}{c}31 \\
\text { (andro- } \\
\text { monoecious) }\end{array}$ & $3: 1$ & 0.91 & 0.34 & $\begin{array}{c}45 \\
\text { (monoecious) }\end{array}$ & $\begin{array}{c}19 \\
\text { (andro- } \\
\text { monoecious) }\end{array}$ & $3: 1$ & 0.52 & 0.47 \\
\hline
\end{tabular}

${ }^{2}$ No amplification or segregation of OAT03.1600, OAW06.1100, OAP03.800, and OAW06.600 in the DT F2 population. 
Table 3. Summary of the simple linear regression (SLR) analysis of marker and data for detection of QTL for eight fruit quality traits including total soluble solids (TSS), sugars, and ascorbic acid (AA) in an $\mathrm{F}_{2}$ population derived from the melon cross of 'TAM Dulce' (high sugars) x TGR1551 (low sugars) in the greenhouse experiment.

\begin{tabular}{|c|c|c|c|c|c|c|c|c|c|c|}
\hline \multirow[b]{2}{*}{ Marker $^{2}$} & \multirow[b]{2}{*}{ Source } & \multirow[b]{2}{*}{ SLR } & \multicolumn{8}{|c|}{ Fruit quality traits } \\
\hline & & & TSS & Sucrose & Glucose & Fructose & SPTS $^{y}$ & GPTS & FPTS & $\mathrm{AA}$ \\
\hline \multirow{2}{*}{ OAT03.1600 } & \multirow{2}{*}{ TAM Dulce } & $P$ & & & & & & 0.041 & & 0.020 \\
\hline & & $R^{2}(\%)$ & & & & & & 4 & & 5 \\
\hline \multirow{2}{*}{ OAU13.1350 } & \multirow{2}{*}{ TAM Dulce } & $P$ & & 0.000 & & & 0.000 & 0.000 & & 0.026 \\
\hline & & $R^{2}(\%)$ & & 10 & & & 13 & 19 & & 5 \\
\hline \multirow{2}{*}{ OAW06.1250 } & \multirow{2}{*}{ TAM Dulce } & $P$ & 0.001 & 0.008 & 0.013 & 0.003 & 0.049 & & & \\
\hline & & $R^{2}(\%)$ & 9 & 7 & 6 & 8 & 4 & & & \\
\hline \multirow{2}{*}{ OAW06.1100 } & \multirow{2}{*}{ TAM Dulce } & $P$ & & & & & & & & 0.039 \\
\hline & & $R^{2}(\%)$ & & & & & & & & 4 \\
\hline \multirow{2}{*}{ OAT03.250 } & \multirow{2}{*}{ TAM Dulce } & $P$ & 0.029 & 0.020 & & 0.012 & 0.027 & 0.002 & & 0.024 \\
\hline & & $R^{2}(\%)$ & 5 & 5 & & 6 & 5 & 9 & & 5 \\
\hline \multirow{2}{*}{ OAA09.350 } & \multirow{2}{*}{ TGR1551 } & $P$ & & 0.000 & & & 0.000 & 0.036 & 0.000 & \\
\hline & & $R^{2}(\%)$ & & 12 & & & 13 & 4 & 13 & \\
\hline \multirow{2}{*}{ OAP03.800 } & \multirow{2}{*}{ TGR1551 } & $P$ & 0.005 & 0.015 & 0.009 & 0.023 & & & 0.038 & \\
\hline & & $R^{2}(\%)$ & 7 & 6 & 6 & 5 & & & 4 & \\
\hline \multirow{2}{*}{ OAQ13.750 } & \multirow{2}{*}{ TGR1551 } & $P$ & & 0.008 & & & 0.013 & 0.008 & & \\
\hline & & $R^{2}(\%)$ & & 7 & & & 6 & 7 & & \\
\hline \multirow{2}{*}{ OAS03.450 } & \multirow{2}{*}{ TGR1551 } & $P$ & 0.004 & 0.015 & 0.010 & 0.024 & & & 0.011 & \\
\hline & & $R^{2}(\%)$ & 8 & 6 & 6 & 5 & & & 6 & \\
\hline \multirow{2}{*}{ OAS14.800 } & \multirow{2}{*}{ TGR1551 } & $P$ & & & & & & & & 0.007 \\
\hline & & $R^{2}(\%)$ & & & & & & & & 7 \\
\hline \multirow{2}{*}{ OAU02.600 } & \multirow{2}{*}{ TGR1551 } & $P$ & & & & & & & & 0.007 \\
\hline & & $R^{2}(\%)$ & & & & & & & & 7 \\
\hline \multirow{2}{*}{ OAU03.700 } & TGR 1551 & $P$ & & & & & & & & 0.003 \\
\hline & IGRIJगI & $R^{2}(\%)$ & & & & & & & & 8 \\
\hline OAU 5600 & TGR 1551 & $P$ & & 0.003 & & & 0.007 & 0.048 & 0.040 & \\
\hline OAU05.600 & IGRIJगI & $R^{2}(\%)$ & & 8 & & & 7 & 4 & 4 & \\
\hline OАW10400 & $\mathrm{T} G \mathrm{P} 1551$ & $P$ & & & & & & & & 0.002 \\
\hline OAW 10.400 & IGRIJगI & $R^{2}(\%)$ & & & & & & & & 9 \\
\hline & & $P$ & 0.010 & 0.000 & & 0.027 & 0.000 & 0.000 & & 0.027 \\
\hline OAW06.600 & TGR1551 & $R^{2}(\%)$ & 6 & 18 & & 5 & 17 & 18 & & 5 \\
\hline$a$ & TGR 1551 & $P$ & 0.044 & 0.046 & & & & & & \\
\hline$a$ & IUKIJगI & $R^{2}(\%)$ & 4 & 4 & & & & & & \\
\hline
\end{tabular}

${ }^{z}$ Marker significantly associated with a trait. $a$ is the andromonoecious gene.

ySPTS $=$ sucrose percentage of total sugars, GPTS = glucose percentage of total sugars, FPTS = fructose percentage of total sugars.

QTL FOR SUCROSE. Nine markers and the $a$ locus were detected to be significantly associated with QTL controlling sucrose content in our population in the greenhouse on the basis of SLR (Table $3)$. High sucrose alleles for these markers were contributed by the high sucrose parent 'TAM Dulce' (Table 4). Three unlinked RAPD markers, generated from 'TAM Dulce', explained 5\% to $10 \%$ of the variation for the sucrose trait. One (OAU13.1350) of the three markers accounting for $10 \%$ of the variation was found using the SMR analysis (Table 5). Six unlinked RAPD markers, produced from TGR 1551, explained $6 \%$ to $18 \%$ of the variation for this trait. An average sucrose value of $\mathrm{F}_{2}$ plants with OAW06.600, the most significantly associated, was $6.4 \mathrm{mg} \cdot \mathrm{g}^{-1}$, while that of $\mathrm{F}_{2}$ plants without OAW06.600 was $12.6 \mathrm{mg} \cdot \mathrm{g}^{-1}$. The difference of the average values between band presence and absence for the marker was $6.2 \mathrm{mg} \cdot \mathrm{g}^{-1}$. Five (OAW06.600, OAA09.350, OAU05.600, OAP03.800, and OAQ13.750) of the six markers were significant in the multilocus model. These markers combined accounted for $39 \%$ of the total variation for the trait.
In peach, two chromosomal regions were observed to be strongly associated with sucrose QTLexplaining 37\% and 39\% of the sucrose variation, respectively (Etienne et al.,2002). Georgelis et al. (2004) recently reported six RAPD markers associated with QTL influencing tomato fruit sugar content, whereas Freeman and Simon (1983) reported simple genetic control of sugar accumulation in carrot (Daucus carota L.).

Schaffer et al. (1996) and Burger et al. (2002) reported a possible association of a sucrose gene with one of the steps of the sucrose metabolism process. Several enzymes including soluble acid invertase, sucrose synthase, and sucrose phosphate synthase involved in the melon fruit sucrose synthesis were reported (Hubbard et al., 1989; Lester et al., 2001; McCollum et al., 1988). Sucrose accumulated in netted muskmelon cultivars only when sucrose phosphate synthase activity was higher than soluble acid invertase activity (Lester et al., 2001). During muskmelon fruit maturation, sucrose phosphate synthase activity was high, whereas soluble acid invertase activity was very low (Lester et 
Table 4. Average values of band absence and presence for each of the 16 markers including andromonoecious $(a)$ associated with total soluble solids (TSS), sugars, and ascorbic acid (AA) in an $\mathrm{F}_{2}$ population derived from the melon cross of 'TAM Dulce' $x$ TGR1551 in the greenhouse experiment.

\begin{tabular}{|c|c|c|c|c|c|c|c|c|c|}
\hline \multirow[b]{2}{*}{ Marker } & \multirow[b]{2}{*}{ Band } & \multicolumn{8}{|c|}{ Fruit quality traits } \\
\hline & & $\begin{array}{l}\text { TSS } \\
(\%)\end{array}$ & $\begin{array}{l}\text { Sucrose } \\
\left(\mathrm{mg}^{-1}\right)\end{array}$ & $\begin{array}{l}\text { Glucose } \\
\left(\mathrm{mgg}^{-1}\right)\end{array}$ & $\begin{array}{c}\text { Fructose } \\
\left(\mathrm{mgg}^{-1}\right)\end{array}$ & $\begin{array}{l}\text { SPTS }^{z} \\
(\%) \\
\end{array}$ & $\begin{array}{c}\text { GPTS } \\
(\%)\end{array}$ & $\begin{array}{c}\text { FPTS } \\
(\%)\end{array}$ & $\begin{array}{c}\text { AA } \\
(\mathrm{mg} / 100 \mathrm{~g})\end{array}$ \\
\hline \multirow{2}{*}{ OAT03.1600 } & Absence & & & & & & 43.7 & & 15.7 \\
\hline & Presence & & & & & & 41.0 & & 19.1 \\
\hline \multirow{2}{*}{ OAU13.1350 } & Absence & & 4.7 & & & 5.5 & 46.9 & & 14.0 \\
\hline & Presence & & 9.1 & & & 12.6 & 40.8 & & 19.0 \\
\hline \multirow{2}{*}{ OAW06.1250 } & Absence & 5.2 & 5.0 & 22.8 & 25.2 & 9.1 & & & \\
\hline & Presence & 6.8 & 8.7 & 27.8 & 31.3 & 12.4 & & & \\
\hline \multirow{2}{*}{ OAW06.1100 } & Absence & & & & & & & & 20.6 \\
\hline & Presence & & & & & & & & 17.5 \\
\hline \multirow{2}{*}{ OAT03.250 } & Absence & 5.7 & 5.6 & & 26.3 & 8.9 & 44.5 & & 16.0 \\
\hline & Presence & 6.7 & 8.7 & & 31.2 & 12.4 & 40.6 & & 19.2 \\
\hline \multirow{2}{*}{ OAA09.350 } & Absence & & 11.9 & & & 17.1 & 38.9 & 43.9 & \\
\hline & Presence & & 6.7 & & & 10.1 & 42.4 & 47.6 & \\
\hline \multirow{2}{*}{ OAP03.800 } & Absence & 7.5 & 10.5 & 30.7 & 33.5 & & & 44.9 & \\
\hline & Presence & 6.1 & 7.0 & 25.4 & 28.7 & & & 47.4 & \\
\hline \multirow{2}{*}{ OAQ13.750 } & Absence & & 10.6 & & & 15.4 & 38.7 & & \\
\hline & Presence & & 6.9 & & & 10.4 & 42.6 & & \\
\hline \multirow{2}{*}{ OAS03.450 } & Absence & 7.0 & 9.7 & 29.4 & 32.4 & & & 45.6 & \\
\hline & Presence & 6.1 & 6.7 & 24.9 & 28.3 & & & 47.6 & \\
\hline \multirow{2}{*}{ OAS14.800 } & Absence & & & & & & & & 21.0 \\
\hline & Presence & & & & & & & & 17.1 \\
\hline \multirow{2}{*}{ OAU02.600 } & Absence & & & & & & & & 21.0 \\
\hline & Presence & & & & & & & & 17.1 \\
\hline \multirow{2}{*}{ OAU03.700 } & Absence & & & & & & & & 21.2 \\
\hline & Presence & & & & & & & & 17.0 \\
\hline \multirow{2}{*}{ OAU05.600 } & Absence & & 10.8 & & & 14.4 & 40.1 & 45.5 & \\
\hline & Presence & & 6.8 & & & 10.5 & 42.2 & 47.3 & \\
\hline \multirow{2}{*}{ OAW 10.400} & Absence & & & & & & & & 21.1 \\
\hline & Presence & & & & & & & & 16.9 \\
\hline \multirow{2}{*}{ OAW06.600 } & Absence & 7.3 & 12.6 & & 33.4 & 16.5 & 37.4 & & 20.8 \\
\hline & Presence & 6.1 & 6.4 & & 28.7 & 9.8 & 43.0 & & 17.5 \\
\hline \multirow[t]{2}{*}{$a$} & $\begin{array}{c}\text { andro- } \\
\text { monoecious }\end{array}$ & 7.1 & 9.6 & & & & & & \\
\hline & monoecious & 6.2 & 7.1 & & & & & & \\
\hline
\end{tabular}

al., 2001). The high sucrose muskmelon cultivar Valley Gold had higher sucrose phosphate synthase activity and lower soluble acid invertase activity than the low sucrose cultivar North Star at the period of fruit abscission (Lester et al., 2001). Our unlinked markers associated with muskmelon fruit sucrose detected here may relate directly or indirectly to these enzymes controlling the sucrose synthesis pathway.

QTL FOR GLUCOSE. Three RAPD markers were significantly associated with QTL regulating glucose content in this genetic population by means of SLR (Table 3). For the three markers the high glucose parent 'TAM Dulce' contributed high glucose alleles (Table 4). Marker OAW06.1250 produced from 'TAM Dulce' explained $6 \%$ of the variation for this trait. Two unlinked markers OAP03.800 and OAS03.450 obtained from TGR1551 were significant in the SMR analysis with a total variation of $11 \%$ for the glucose trait (Table 5).

QTL FOR FRUCTOSE. Two unlinked markers OAW06.1250 and OAT03.250 obtained from 'TAM Dulce' and three unlinked markers OAP03.800, OAW06.600, and OAS03.450 derived from TGR1551 were associated with QTL for fructose concentration in our genetic population by SLR (Table 3). For the RAPD markers, high fructose alleles were contributed by the high fructose parent 'TAM Dulce' (Table 4). In the SMR analysis the two groups of markers were significant with total $R^{2}$ values of $15 \%$ and $13 \%$ for this trait, respectively (Table 5).

QTL FOR SUCROSE PERCENTAGE OF TOTAL SUGARS. Seven significant assciations between RAPD marker loci and QTL influencing SPTS were identified in this population based on SLR (Table 3). The 'TAM Dulce' parent contributed high SPTS alleles for these seven markers (Table 4). Markers OAU13.1350, OAT03.250, and OAW06.1250 from 'TAM Dulce' explained 4\% to $13 \%$ of the variation for this trait. Only one of the three unlinked markers accounting for $13 \%$ of the variation was noted using the SMR analysis (Table 5). Markers OAW06.600, OAA09.350, OAU05.600, and OAQ13.750 from TGR1551 explained 6\% to $17 \%$ of the variation for this trait. Three of the four unlinked markers were significant in the full model, and accounted for $31 \%$ of the total variation for the trait.

QTL FOR GLUCOSE PERCENTAGE OF TOTAL SUGARS. On the basis of SLR a total of seven associations of markers with QTL affect- 
Table 5. Summary of the stepwise multiple regression (SMR) analysis of marker and data for detection of QTL for eight fruit quality traits including total soluble solids (TSS), sugars, and ascorbic acid (AA) in an $\mathrm{F}_{2}$ population derived from the melon cross of 'TAM Dulce' (high sugars) x TGR1551 (low sugars) in the greenhouse experiment.

\begin{tabular}{|c|c|c|c|c|c|c|c|c|c|c|}
\hline \multirow[b]{2}{*}{ Marker $^{2}$} & \multirow[b]{2}{*}{ Source } & \multirow[b]{2}{*}{ SMR } & \multicolumn{8}{|c|}{ Fruit quality traits } \\
\hline & & & TSS & Sucrose & Glucose & Fructose & SPTS $^{y}$ & GPTS & FPTS & AA \\
\hline \multirow{2}{*}{ OAT03.1600 } & \multirow{2}{*}{ TAM Dulce } & $P$ & & & & & & & & 0.020 \\
\hline & & $R^{2}(\%)$ & & & & & & & & 5 \\
\hline \multirow{2}{*}{ OAU13.1350 } & \multirow{2}{*}{ TAM Dulce } & $P$ & & 0.000 & & & 0.000 & 0.000 & & \\
\hline & & $R^{2}(\%)$ & & 10 & & & 13 & 19 & & \\
\hline \multirow{2}{*}{ OAW06.1250 } & \multirow{2}{*}{ TAM Dulce } & $P$ & 0.001 & & 0.013 & 0.003 & & & & \\
\hline & & $R^{2}(\%)$ & 9 & & 6 & 8 & & & & \\
\hline \multirow{2}{*}{ OAW06.1100 } & \multirow{2}{*}{ TAM Dulce } & $P$ & & & & & & & & 0.033 \\
\hline & & $R^{2}(\%)$ & & & & & & & & 4 \\
\hline \multirow{2}{*}{ OAT03.250 } & \multirow{2}{*}{ TAM Dulce } & $P$ & 0.014 & & & 0.005 & & & & 0.025 \\
\hline & & $R^{2}(\%)$ & 5 & & & 7 & & & & 5 \\
\hline \multicolumn{2}{|c|}{ Cumulative $R^{2}$} & & 14 & 10 & 6 & 15 & 13 & 19 & & 14 \\
\hline \multirow{2}{*}{ OAA09.350 } & \multirow{2}{*}{ TGR1551 } & $P$ & & 0.001 & & & 0.000 & & 0.000 & \\
\hline & & $R^{2}(\%)$ & & 8 & & & 9 & & 13 & \\
\hline \multirow{2}{*}{ OAP03.800 } & \multirow{2}{*}{ TGR1551 } & $P$ & 0.011 & 0.009 & 0.009 & 0.024 & & & & \\
\hline & & $R^{2}(\%)$ & 6 & 4 & 6 & 5 & & & & \\
\hline \multirow{2}{*}{ OAQ13.750 } & \multirow{2}{*}{ TGR1551 } & $P$ & & 0.044 & & & & 0.026 & & \\
\hline & & $R^{2}(\%)$ & & 3 & & & & 4 & & \\
\hline \multirow{2}{*}{ OAS03.450 } & \multirow{2}{*}{ TGR1551 } & $P$ & 0.004 & & 0.021 & 0.047 & & & 0.007 & \\
\hline & & $R^{2}(\%)$ & 8 & & 5 & 3 & & & 6 & \\
\hline \multirow{2}{*}{ OAU05.600 } & \multirow{2}{*}{ TGR1551 } & $P$ & & 0.002 & & & 0.008 & 0.037 & & \\
\hline & & $R^{2}(\%)$ & & 6 & & & 5 & 3 & & \\
\hline \multirow{2}{*}{ OAW 10.400} & \multirow{2}{*}{ TGR1551 } & $P$ & & & & & & & & 0.002 \\
\hline & & $R^{2}(\%)$ & & & & & & & & 9 \\
\hline \multirow{2}{*}{ OAW06.600 } & \multirow{2}{*}{ TGR1551 } & $P$ & 0.011 & 0.000 & & 0.026 & 0.000 & 0.000 & & 0.047 \\
\hline & & $R^{2}(\%)$ & 5 & 18 & & 5 & 17 & 18 & & 3 \\
\hline \multicolumn{2}{|c|}{ Cumulative $R^{2}$} & & 19 & 39 & 11 & 13 & 31 & 25 & 19 & 12 \\
\hline
\end{tabular}

zMarker significantly associated with a trait.

ySPTS = sucrose percentage of total sugars, GPTS = glucose percentage of total sugars, FPTS = fructose percentage of total sugars.

ing GPTS were detected in the population (Table 3). Three and four unlinked markers were amplified from 'TAM Dulce' and TGR1551, respectively. High GPTS alleles for these markers were contributed by the TGR 1551 parent (Table 4). OAU13.1350 from 'TAM Dulce' explained $19 \%$ of the variation for this trait, while AT03.250 and OAT03.1600 from 'TAM Dulce' accounted for $9 \%$ and $4 \%$ of the variation, respectively. However, only OAU13.1350 was significantly associated using the SMR analysis (Table 5). OAW06.600 from TGR 1551 explained 18\% of the variation for this trait. Three marker loci OAW06.600, OAQ13.750, and OAU05.600 accounting for $25 \%$ of the total variation were significant in the SMR analysis.

QTL FOR FRUCTOSE PERCENTAGE OF TOTAL SUGARS. We identified significant associations of four unlinked RAPD markers, generated only from TGR1551, with QTL controlling FPTS by means of SLR (Table 3). For the four markers, the TGR1551 parent contributed high FPTS alleles (Table 4). OAA09.350 explained $13 \%$ of the variation for this trait. OAA09.350 and OAS03.450 were significant in the SMR analysis with a total FPTS variation of $19 \%$ (Table 5).

QTL FOR ASCORBIC ACID. Nine RAPD markers, four produced from 'TAM Dulce' and five obtained from TGR1551, were associated with QTL regulating AA concentration in our popula- tion based on SLR (Table 3). For the genetic markers, except OAW06.1100, high AA alleles were contributed by the 'TAM Dulce' parent (Table 4). These four unlinked markers accounted for $4 \%$ to $5 \%$ of the variation for the AA trait. Three markers OAT03.1600, OAT03.250, and OAW06.1100 from 'TAM Dulce', explaining $14 \%$ of the total variation for the trait, were detected using the SMR analysis (Table 5). The five TGR1551 markers each accounted for $5 \%$ to $9 \%$ of the variation for the vitamin C trait. Two unlinked markers OAW 10.400 and OAW06.600 from TGR1551 were significant in the SMR with a total $R^{2}$ of $12 \%$.

Etienne et al. (2002) mapped a single QTL with major effect influencing organic acid content such as malic acid, citric acid, and quinic acid on LGs 5 and 8 on a peach linkage map. Causse et al. (2002) tagged QTL affecting antioxidant compounds including lycopene and carotene content on a tomato linkage map. A major QTL controlling titratable acidity and $\mathrm{pH}$ was reported in peach (Etienne et al., 2002), whereas few to many QTL affecting the two traits were found in several tomato populations (Causse et al., 2002; Georgelis et al., 2004; Paterson et al., 1991). However, this is the first report of RAPD markers associated with QTL for the important antioxidant, vitamin C, in melon. Among watermelon and several melon types, muskmelons possessed the highest vitamin C content (Pratt, 1971). Therefore, these nine markers 
Table 6. Confirmation of eight RAPD markers and andromonoecious (a) associated with QTL for eight fruit quality traits including total soluble solids (TSS), sugars, and ascorbic acid (AA) in an $\mathrm{F}_{2}$ population derived from the melon cross of 'Deltex' (high sugars) x TGR1551 (low sugars) in the field experiment.

\begin{tabular}{|c|c|c|c|c|c|c|c|c|c|c|}
\hline \multirow[b]{2}{*}{ Marker $^{2}$} & \multirow[b]{2}{*}{ Source } & \multirow[b]{2}{*}{ SLR $^{y}$} & \multicolumn{8}{|c|}{ Fruit quality traits } \\
\hline & & & TSS & Sucrose & Glucose & Fructose & SPTS $^{x}$ & GPTS & FPTS & $\mathrm{AA}$ \\
\hline \multirow{2}{*}{ OAU13.1350 } & TAM Dulce & $P$ & & 0.040 & & & 0.047 & 0.001 & & 0.000 \\
\hline & \& Deltex & $R^{2}(\%)$ & & 4 & & & 4 & 9 & & 14 \\
\hline \multirow[b]{2}{*}{ OAW06.1250 } & TAM Dulce & $P$ & 0.046 & 0.002 & 0.026 & 0.039 & 0.000 & & & \\
\hline & $\&$ Deltex & $R^{2}(\%)$ & 4 & 9 & 5 & 4 & 10 & & & \\
\hline \multirow{2}{*}{ OAA09.350 } & \multirow{2}{*}{ TGR1551 } & $P$ & & 0.006 & & & 0.000 & 0.000 & 0.000 & \\
\hline & & $R^{2}(\%)$ & & 7 & & & 12 & 11 & 13 & \\
\hline \multirow{2}{*}{ OAS03.450 } & \multirow{2}{*}{ TGR1551 } & $P$ & 0.000 & & 0.037 & 0.011 & & & & \\
\hline & & $R^{2}(\%)$ & 17 & & 4 & 6 & & & & \\
\hline \multirow{2}{*}{ OAS14.800 } & \multirow{2}{*}{ TGR1551 } & $P$ & & & & & & & & 0.012 \\
\hline & & $R^{2}(\%)$ & & & & & & & & 6 \\
\hline \multirow{2}{*}{ OAU02.600 } & \multirow{2}{*}{ TGR1551 } & $P$ & & & & & & & & 0.036 \\
\hline & & $R^{2}(\%)$ & & & & & & & & 4 \\
\hline \multirow{2}{*}{ OAU03.700 } & \multirow{2}{*}{ TGR1551 } & $P$ & & & & & & & & 0.014 \\
\hline & & $R^{2}(\%)$ & & & & & & & & 6 \\
\hline \multirow{2}{*}{ OAU05.600 } & \multirow{2}{*}{ TGR1551 } & $P$ & & 0.008 & & & 0.041 & & 0.000 & \\
\hline & & $R^{2}(\%)$ & & 7 & & & 4 & & 10 & \\
\hline \multirow{2}{*}{$a$} & \multirow{2}{*}{ TGR1551 } & $P$ & 0.000 & 0.000 & & & & & & \\
\hline & & $R^{2}(\%)$ & 18 & 15 & & & & & & \\
\hline
\end{tabular}

zMarker significantly associated with a trait.

ySLR = simple linear regression.

xSPTS = sucrose percentage of total sugars, GPTS = glucose percentage of total sugars, FPTS $=$ fructose percentage of total sugars.

identified in the muskmelon type could be at least partially utilized in improving the level of this nutrient in new melon cultivars.

COMMON MARKERS FOR FRUIT SWEETNESS TRAITS. We observed that of the 15 RAPD markers for fruit quality traits, 10 were consistently associated with two to six fruit quality traits in this greenhouse population from the 'TAM Dulce' $x$ TGR1551 cross (Table 3). MarkerOAU13.1350 from 'TAMDulce' was associated with sucrose, SPTS, GPTS, and AA, and accounted for $5 \%$ to $19 \%$ of the variation for these traits. Marker OAW06.1250 from 'TAM Dulce' was associated with five sugar traits-TSS, sucrose, glucose, fructose, and SPTS, indicating that this RAPD marker could be useful in selecting the five major sugar traits simultaneously. We found slight associations of OAT03.250 from 'TAM Dulce' with six traits including TSS, sucrose, fructose, SPTS, GPTS, and AA, while we noted high associations of OAW06.600 from TGR 1551 with the six traits. The OAW06.600 marker explained 5\% to $18 \%$ of the variation for those traits. OAA09.350 was associated with sucrose and three individual sugar compositions, and accounted for $4 \%$ to $13 \%$ of the variation for the traits. Clusters of QTL in a genomic region controlling several melon fruit size and shape traits (Park and Crosby, 2004; Perin et al., 2002a), tomato fruit size and quality traits (Causse et al., 2002; Georgelis et al., 2004), peach fruit sweetness and quality traits (Etienne et al., 2002), and bean disease resistance (Park et al., 1999) have been reported.

Confirmation of THE MARKer-QTL association. Confirmation of the associations of the RAPD and andromonoecious markers with QTL for the fruit quality traits identified in the $\mathrm{F}_{2}$ population of the 'TAM Dulce' $x$ TGR1551 cross in the greenhouse was needed in other populations of the same cross and or a different cross in different environments to substantiate their merit in melon breeding. Of the 15 RAPD markers associated with the fruit quality traits detected in the greenhouse population, 11 were also polymorphic between the parents 'Deltex' and TGR1551 (Fig. 3 ) that were utilized to create the $F_{2}$ population from which the eight fruit quality traits were evaluated in the field experiment (Table 2). Due to either no amplification of OAT03.1600 and OAW06.1100 or no segregation of OAP03.800 and OAW06.600 in the parents 'Deltex' and TGR1551, the remaining four markers were not tested for confirming the marker-QTL association. All 11 markers also segregated in the $\mathrm{F}_{2}$ population of the 'Deltex' x TGR1551 cross. A 3:1 goodness-of-fit ratio for band presence to band absence for each of the 11 markers, three amplified from 'Deltex' and eight amplified from TGR1551, was observed in the field population (Table 2). Eight RAPD markers associated with the sugar and AA traits in the greenhouse experiment were confirmed in the $F_{2}$ population of the 'Deltex' $x$ TGR 1551 cross in the field experiment to be consistently associated with QTL for the fruit quality traits based on SLR (Table 6). Marker OAA09.350 obtained from TGR1551 associated with QTL for the four sugar traits - sucrose, SPTS, GPTS, and FPTS - in the greenhouse population was also found to be significantly associated with QTL for the four traits in the field population, and accounted for $7 \%$ to $13 \%$ of the variation for the sugar traits. Significant associations of OAW06.1250 from 'Deltex' with QTL for the 
five sugar traits were consistently expressed in our populations derived from two different crosses under greenhouse and field environments, and explained $4 \%$ to $10 \%$ of the variation for the five traits. OAU13.1350 from 'Deltex' associated with the four quality traits in the greenhouse was also significantly associated with the quality traits in the field, and accounted for $4 \%$ to $14 \%$ of the variation for the traits. We noted consistent aassociations of OAU05.600 and OAS03.450 with three sugar traits in the different populations under greenhouse and field conditions. Markers OAS14.800, OAU02.600, and OAU03.700 were associated only with the vitamin $\mathrm{C}$ content in the greenhouse and field. However, three markers (OAT03.250, OAQ13.750, and OAW10.400), slightly associated with the fruit quality traits identified in the greenhouse $\mathrm{F}_{2}$ population, were not confirmed in this field $\mathrm{F}_{2}$ population.

The andromonoecious locus regulating stamen absence or stamen presence in female flowers was observed to be weakly but significantly associated with both TSS and sucrose traits in the 'TAM Dulce' $x$ TGR 1551 cross in the greenhouse (Table 3). These associations were confirmed in the high sugar andromonoecious 'Deltex' $x$ the low sugar monoecious TGR1551 cross in the field (Table 6). The $a$ locus highly associated with the TSS and sucrose traits in the field population accounted for $18 \%$ and $15 \%$ of the variation for the traits, respectively. According to the result of Pitrat (1991), the andromonoecious marker was loosely linked to zucchini yellow mosaic virus resistance Zym, powdery mildew resistance $P m-x$, and halo cotyledons $h$ on LG 4 of the classical map. The $a$ marker was highly associated with QTL for fruit size and shape traits in $\mathrm{F}_{2}$ and recombinant inbred populations from different crosses (Park and Crosby, 2004; Perin et al., 2002a). Particularly, the flower marker was tightly linked to major QTL on LG 4 or LG II of a molecular map, accounting for $48 \%$ and $47 \%$ of the phenotypic variation for fruit length based on different statistical analyses, respectively. We found consistent associations of OAP03.800 on the consensus LG with TSS, three sugar components, and FPTS in our greenhouse study. Pitrat (2002) also included QTL for cucumber mosaic virus resistance, ethylene production, and ovary shapes on the same LG. The pentamerous ( $p$ ) gene on LG XII was also linked to major fruit shape QTL (Perin et al., 2002a).

Trait correlations, if genetic in nature, imply either genetic linkage of genes controlling variation for each trait or pleiotropic control of both traits by a single gene. Correlated traits usually have common markers associated with them (Paterson et al., 1991). Six of the 10 RAPD and $a$ markers associated with sucrose were also observed to be significantly associated with TSS in the greenhouse population (Table 3), indicating that the common markers associated with QTL affecting both sucrose and TSS, particularly OAW06.1250 from 'TAM Dulce' and OAW06.600 from TGR1551, could be used as single dominant or codominant markers for simultaneous selection of the two most important fruit sweetness traits. Three and five of the 10 markers associated with sucrose were also associated with glucose and fructose in the greenhouse study, respectively. Where all six positive correlations were found between four major sugar traits in the greenhouse, we noted three common associated markers including OAW06.1250, OAP03.800, and OAS03.450 for TSS and three individual sugars. These results suggest that TSS, sucrose, glucose, and fructose could be controlled at least partially by the same major and minor genes or tight coupling-phase linked genes. These RAPD markers and the andromonoecious trait associated with the sugar synthesis QTL could be useful to transfer these genes into a low sugar cultivar or breeding line to enhance the mature melon fruit sweetness.

Compared to the initial stage of fruit development, multiple increases of sucrose content in the muskmelon 'TAM Perlita' were observed at the stage of fruit maturation under greenhouse and field conditions, whereas a great reduction of glucose and fructose content was found at the same stage (Lester and Dunlap, 1985). The decrease of the glucose content was greater than that of the fructose content in both environments. Because of the loss of the glucose and fructose content, the remarkable increase of sucrose content in the muskmelon cultivar was feasible at harvest (Lester and Dunlap, 1985), indicating the important contributions of the two monosaccharides, especially glucose, in sucrose accumulation. Thus, those markers associated with the glucose and fructose content detected here could be potentially utilized in melon breeding for the elevated sucrose trait.

Among 29 QTL affecting fruit size, TSS, and $\mathrm{pH}$ in a tomato cross, only four were expressed in three environments (Paterson et al., 1991). Of six QTL for resistance to common bacterial blight, incited by Xanthomonas campestris pv. phaseoli (Smith) Dye, only two were expressed in three common bean populations (Park et al., 1999). These results show the importance of confirming the marker-QTL associations in other environments and populations before using markers for MAS in a breeding program. Therefore, our confirmation of the identified marker-QTL associations in different populations and environments is an essential step for universal use of our linked markers in melon breeding. The RAPD and $a$ markers linked to QTL for comprehensive sugar traits identified and confirmed in two populations and environments here should be more reliable for MAS than those evaluated in a single population and environment.

\section{Literature Cited}

Adams, C.F. and M. Richardson. 1981. Nutritive value of foods. USDA Home and Garden Bul. 72. U.S. Government Printing Office, Washington D.C.

Baudracco-Arnas, S. and M. Pitrat. 1996. A genetic map of melon ( $\mathrm{Cu}$ cumis melo L.) with RFLP, RAPD, isozyme, disease resistance and morphological markers. Theor. Appl. Genet. 93:57-64.

Brotman, Y., L. Silberstein, I. Kovalski, J. Klingler, G. Thompson, N. Katzir, and R. Perl-Treves. 2000. Linkage groups of Cucumis melo, including resistance gene homologues and known genes. Acta Hort. 510:441-448.

Burger, Y., U. Saar, N. Katzir, H. Paris, Y. Yeselson, I. Levin, and A. Schaffer. 2002. A single recessive gene for sucrose accumulation in Cucumis melo fruit. J. Amer. Soc. Hort. Sci. 127:938-943.

Causse, M., V. Saliba-Colombani, L. Lecomte, P. Duffe, P. Rousselle, and M. Buret. 2002. QTL analysis of fruit quality in fresh market tomato: A few chromosomal regions control the variation of sensory and instrumental traits. J. Expt. Bot. 53:2089-2098.

Danin-Poleg, Y., N. Reis, G. Tzuri, and N. Katzir. 2001. Development and characterization of microsatellite markers in Cucumis. Theor. Appl. Genet. 102:61-72.

Danin-Poleg, Y., N. Reis, S. Baudracco-Arnas, M. Pitrat, J.E. Staub, M. Oliver, P. Arús, C.M. de Vicente, and N. Katzir. 2000. Simple sequence repeats in Cucumis mapping and map merging. Genome 43:963-974.

Danin-Poleg, Y., Y. Tadmor, G. Tzuri, N. Reis, J. Hirschberg, and N. Katzir. 2002. Construction of a genetic map of melon with molecular markers and horticultural traits, and localization of genes associated with ZYMV resistance. Euphytica 125:373-384.

Edwards, M.D., C.W. Stuber, and J.F. Wendell. 1987. Molecular marker-facilitated investigations of quantitative trait loci in maize. I. Numbers, genomic distribution, and types of gene action. Genetics 116:113-125. 
Eichholzer, M., J. Luthy, F. Gutzwiller, and H.B. Stahelin. 2001. The role of folate, antioxidant vitamins and other constituents in fruit and vegetables in the prevention of cardiovascular disease: The epidemiological evidence. Intl. J. Vitamin Nutr. Res. 71:5-17.

Etienne, C., C. Rothan, A Moing, C. Plomion, C. Bodenes, L. SvanellaDumas, P. Cosson, V. Pronier, R. Monet, and E. Dirlewanger. 2002. Candidate genes and QTLs for sugar and organic acid content in peach [Prunus persica (L.) Batsch]. Theor. Appl. Genet.105:145-159.

Freeman, R.E. and P.W. Simon. 1983. Evidence for simple genetic control of sugar type in carrot (Daucus carota L.). J. Amer. Soc. Hort. Sci. 108:50-54.

Georgelis, N., J.W. Scott, and E.A. Baldwin. 2004. Relationship of tomato fruit sugar concentration with physical and chemical traits and linkage of RAPD markers. J. Amer. Soc. Hort. Sci. 129:839-845.

Hashizume, T., I. Shimamoto, and M. Hirai. 2003. Construction of a linkage map and QTL analysis of horticultural traits for watermelon [Citrullus lanatus (Thunb.) Matsum and Nakai] using RAPD, RFLP and ISSR markers. Theor. Appl. Genet. 106:779-785.

Hodges, D.M., C.F. Forney, and W.V.Wismer. 2001.Antioxidant responses in harvested leaves of two cultivars of spinach differing in senescence rates. J. Amer. Soc. Hort. Sci. 126:611-617.

Hubbard, N.L., S.C. Huber, and D.M. Pharr. 1989. Sucrose photosynthate synthase and acid invertase as determinants of sucrose concentration in developing muskmelon (Cucumis melo L.) fruits. Plant Physiol 91:1527-1534.

Hughes, D.L. and M. Yamaguchi. 1983. Identification and distribution of some carbohydrates of the muskmelon plant. HortScience 18:739-740.

Kalb, T.J. and D.W. Davis. 1984. Evaluation of combining ability, heterosis, and genetic variance for fruit quality characteristics in bush muskmelon. J. Amer. Soc. Hort. Sci. 109:411-415.

Klingler, J., I. Kovalski, L. Silberstein, G.A. Thompson, and R. PerlTreves. 2001. Mapping of cotton-melon aphid resistance in melon. J. Amer. Soc. Hort. Sci. 126:56-63.

Kosambi, D.D. 1944. The estimation of map distances from recombination values. Ann. Eugenics 12:172-175.

Kunkel, H.O. 1968. Dulce cantaloupe. Texas Agricultural Experiment Station bulletin L-760, Texas A\&M Univ., College Station.

Lander, E.S., P. Green, J.Abrahamson, A. Barlow, M.J. Daly, S.E. Lincoln, and L. Newburg. 1987. MAPMAKER: An interactive computer package for constructing primary genetic linkage maps with experimental and natural populations. Genomics 1:174-181.

Lavine, M. 1986. New concepts in the biology and biochemistry of ascorbic acid. New England J. Medicine 314:892-902.

Lester, G. 1997. Melon (Cucumis melo L.) fruit nutritional quality and health functionality. HortTechnology 7:222-227.

Lester, G.E. and J.R. Dunlap. 1985. Physiological changes during development and ripening of 'Perlita' muskmelon fruits. Scientia Hort. 26:323-331.

Lester, G.E. and K.C. Shellie. 1992. Postharvest sensory and physicochemical attributes of honey dew melon fruits. HortScience 27:1012-1014.

Lester, G.E., L.S. Arias, and M. Gomez-Lim. 2001. Muskmelon fruit soluble acid invertase and sucrose phosphate synthase activity and polypeptide profiles during growth and maturation. J. Amer. Soc. Hort. Sci. 126:33-36.

Lopez-Sese, A.I. and M.L. Gomez-Guillamon. 2000. Resistance to cucurbit yellowing stunting disorder virus (CYSDV) in Cucumis melo L. HortScience 35:110-113.

Martyn,R.D. and M.E. Miller. 1996. Monosporascus root rot/vine decline: An emerging disease of melons worldwide. Plant Dis. 80:716-725.

McCollum, T.G., D.J. Huber, and D.J. Cantliffe. 1988. Soluble sugar accumulation and activity of related enzymes during muskmelon fruit development. J. Amer. Soc. Hort. Sci. 113:399-403.

Michelmore, R.W., I. Paran, and R.V. Kesseli. 1991. Identification of markers linked to disease resistance genes by bulked segregant analysis: A rapid method to detect markers in specific genomic regions using segregating populations. Proc. Natl. Acad. Sci. USA 88:9828-9832.

Morales, M., M. Luis-Arteaga, J.M. Alvarez, R. Dolcet-Sanjuan, A.
Monfort, P. Arus, and J. Garcia-Mas. 2002. Marker saturation of the region flanking the gene $N S V$ conferring resistance to the melon necrotic spot Carmovirus (MNSV) in melon. J. Amer. Soc. Hort. Sci. 127:540-544.

Oliver, M., J. Garcia-Mas, M. Cardús, N. Pueyo, A.I. López-Sesé, M. Arroyo, H. Gómez-Paniagua, P.Arús, and M.C. de Vicente. 2001. Construction of a reference linkage map for melon. Genome 44:836-845.

Park, S.O., D.P. Coyne, J.R. Steadman, K.M. Crosby, and M.A. Brick. 2004a. RAPD and SCAR markers linked to the Ur-6 Andean gene controlling specific rust resistance in common bean. Crop Sci. 44:1799-1807.

Park, S.O., D.P. Coyne, N. Mutlu, G. Jung, and J.R. Steadman. 1999. Confirmation of molecular markers and flower color associated with QTL for resistance to common bacterial blight in common beans. J. Amer. Soc. Hort. Sci. 124:519-526.

Park, S.O. and K.M. Crosby. 2004. Detection of QTL controlling fruit size and shape in Cucumis melo L. HortScience 39:774. (Abstr.)

Park, S.O., K.M. Crosby, J.W. Sinclair, K.S. Yoo, and L.M. Pike. 2004b. Identification of QTL affecting sugars in ananas melon. HortScience 39:774. (Abstr.)

Park, S.O., K.M. Crosby, R.F. Huang, and T.E. Mirkov. 2004c. Identification and confirmation of RAPD and SCAR markers linked to the $m s-3$ gene controlling male sterility in melon (Cucumis melo L.). J. Amer. Soc. Hort. Sci. 129:819-825.

Paterson, A.H., S. Damon, J.D. Hewitt, D. Zamir, H.D. Rabinowitch, S.E. Lincoln, E.S. Lander, and S.D. Tanksley. 1991. Mendelian factors underlying quantitative traits in tomato: Comparison across species, generations, and environments. Genetics 127:181-197.

Perin, C., L.S. Hagen, N. Giovinazzo, D. Besombes, C. Dogimont, and M. Pitrat. 2002a. Genetic control of fruit shape acts prior to anthesis in melon (Cucumis melo L.). Mol. Genet. Genomics 266:933-941.

Perin, C., L.S. Hagen, V. de Conto, N. Katzir, Y. Danin-Poleg, V. Portnoy, S. Baudracco-Arnas, J. Chadoeuf, C. Dogimont, and M. Pitrat. 2002b. A reference map of Cucumis melo based on two recombinant inbred line populations. Theor. Appl. Genet. 104:1017-1034.

Pitrat, M. 1991. Linkage groups in Cucumis melo L. J. Heredity 82:406-411.

Pitrat, M. 2002. 2002 gene list for melon. Cucurbit Genet. Coop. Rpt. 25:76-93.

Pratt, H.K. 1971. Melons, p. 207-232. In: A.C. Hulme (ed.). The biochemistry of fruit and their products. Vol. 2. Academic Press, New York.

Richter, H. 2000. Fresh produce guide: Nutrition, selection, preparation, storage, handling, cooking tips. Try-Foods Intl., Apopka, Fla.

Rosa, J.T. 1928. Changes in composition during ripening and storage of melons. Hilgardia 3:421-443.

Schaffer, A.A., D.M. Pharr, and M.A. Madore. 1996. Cucurbits, p. 729-757. In: E. Zamski and A.A. Schaffer (eds.). Photoassimilate distribution in plants and crops. Marcel Dekker, New York.

Skroch, P.W. and J. Nienhuis. 1995. Qualitative and quantitative characterization of RAPD variation among snap bean genotypes. Theor. Appl. Genet. 91:1078-1085.

U.S. Government Printing Office. 1990. Code of Federal regulations 7C-FR979.304. U.S. Government Printing Office, Washington, D.C. Wang, Y.H., C.E. Thomas, and R.A. Dean. 1997. A genetic map of melon (Cucumis melo L.) based on amplified fragment length polymorphism (AFLP) markers. Theor. Appl. Genet. 95:791-798.

Wechter, W.P., M.P. Whitehead, C.E. Thomas, and R.A. Dean. 1995. Identification of a randomly amplified polymorphic DNA marker linked to the Fom 2 fusarium wilt resistance gene in muskmelon MR1. Phytopathology 85:1245-1249.

Welles, G.W.H. and K. Buitelaar. 1988. Factors affecting soluble solids content of muskmelon (Cucumis melo L.). Netherlands J. Agr. Sci. 36:239-246.

Williams, J.G.K.,A.R. Kubelik, K.J.Livak, J.A. Rafalksi, and S.V. Tingey. 1990. DNA polymorphisms amplified by arbitrary primers are useful as genetic markers. Nucleic Acids Res. 18:6531-6535.

Yamaguchi, M., D.L. Hughes, K. Yabumoto, and W.C. Jennings. 1977. Quality of cantaloupes: Variability and attributes. Scientia Hort. 6:59-70. 